\title{
Obituary: Professor Toshiro Terano
}

\author{
MICHIO SUGENO \\ Faculty of Culture and Information Science, Doshisha University \\ TAKEHISA ONISAWA \\ Graduate School of Systems and Information Engineering, University of Tsukuba
}

We wish to inform you with deep regret and sorrow that Professor Toshiro Terano passed away due to heart failure on February 15.

Born in 1922, Professor Terano graduated from Department of Mechanical Engineering at The University of Tokyo in 1945 . He completed the graduate course at the University of Tokyo in 1947 and received his Ph.D. from The University of Tokyo in 1960.

Professor Terano joined in the then Ministry of Transportation (the present Ministry of Land, Infrastructure and Transportation) in 1947. His research focus was control engineering, in particular, the control of boiler systems. He received an award for his paper "Dynamic Analysis of Once-Through Boiler" from The Japan Society of Mechanical Engineering in 1959; this paper was subsequently translated into German. He was one of the pioneers in control engineering in Japan. He joined the Department of Control Engineering at Tokyo Institute of Technology as a professor in 1962 where he taught feedback control and systems engineering. After joining T.I.T., he served as a member of the liaison committee on automatic control of The Science Council of Japan and as a member of the power reactor demonstration team at the Japan Atomic Energy Research Institute.

Professor Terano's research interest in control engineering gradually shifted to large-scale and complex systems which include humans. He published many papers and books on failure diagnosis, human reliability, safety analysis, macroscopic analysis of large-scale and complex systems. In 1975, he received an award for his work on the safety of complex systems from The Society of Instrument and Control Engineers. He played a key role in establishing the Department of Systems Science in the graduate school of Tokyo Institute of Technology in 1975. He retired from T.I.T in 1982 with an emeritus professorship. After retirement from T.I.T., he worked at Hosei University.

He supervised many doctoral students and researchers at T.I.T and Hosei University, who are currently active in various fields. At the head of the list of them are Professor Sugeno and Professor Tsukamoto who served Professor Terano as research associates. Over the last 30 years, the research of Professor Toshiro Terano was focused on fuzzy theory and its application to systems engineering. He was interested in fuzzy theory as a methodology for dealing macroscopically with problems in complex systems and advocated "fuzzy engineering" as the application of 
fuzzy theory to engineering problems. He was truly a pioneer in fuzzy engineering. He initiated the Working Group on Fuzzy Systems in Japan in 1972. This working group published the research report, Summary of Papers on General Fuzzy Problems, annually from 1975. This working group, together with the other research group on fuzzy science, grew into the Japanese chapter of the International Fuzzy Systems Association (IFSA). Professor Terano served as chairman of the organizing committee of the 2nd IFSA World Congress held in Tokyo in 1987. This world congress showed fuzzy researchers all over the world successful results in fuzzy theory and its applications in Japan. The Japan Society for Fuzzy Theory and Systems (the present Japan Society for Fuzzy Theory and Intelligent Informatics, SOFT) was established as a development of the Japanese chapter of IFSA in 1989 and Professor Terano was one of the leading founding members of SOFT. He served as the president of IFSA from 1991 through 1993. He was also the director of the Laboratory for International Fuzzy Engineering Research (LIFE) from 1989 through 1995 during which time he invited many distinguished researchers from abroad to visit LIFE. He encouraged many young researchers to pursue fuzzy engineering aimed at human friendly systems. As organizing committee chair, Professor Terano promoted two international conferences sponsored by LIFE, the International Fuzzy Engineering Symposium (IFES) in 1991 and the Joint International Conference of FUZZ-IEEE and IFES in 1995.

Professor Terano published more than 20 books, more than 80 papers and more than 100 survey papers constituting leading research in three fields, control engineering, systems engineering and fuzzy engineering. He served, as a member of editorial board or advisory editor of many international journals including Fuzzy Sets and Systems and Fuzzy Optimization and Decision Making. Besides many paper awards, he received the Moisil Prize from Romania in 1993, the Recognition Award from SOFT in 1994, the Kampé de Fériet Prize from France in 1996, and The Order of the Sacred Treasure, Gold Rays with Neck Ribbon from the Japanese government in 1997.

For all of us, the researchers in fuzzy theory, soft computing and related fields throughout the world, it is difficult to accept the passing of Professor Terano. We have lost a great leader and a great friend with an open mind. We all pray that Professor Terano's soul may rest in peace. 